\title{
h०ª
}

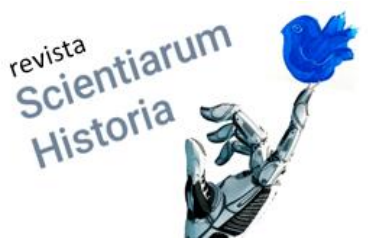

Manufacturing living beings: a brazilian biofactory

\section{Produzindo seres vivos: uma biofábrica brasileira}

\author{
Cláudia Santos Turco \\ Programa de Pós-graduação em História das Ciências e das Técnicas e Epistemologia, \\ Universidade Federal do Rio de Janeiro \\ claudia.turco@hcte.ufrj.br \\ Eduardo Nazareth Paiva \\ Programa de Pós-graduação em História das Ciências e das Técnicas e Epistemologia, \\ Universidade Federal do Rio de Janeiro \\ edu@hcte.ufrj.br
}

Recebido: 27/04/2021 Aceito: 29/04/2021 Publicado: 04/05/2021

DOI: $10.51919 /$ revista_sh.v1i0.275

\begin{abstract}
Human beings use other living beings as objects, be they animals, plants or micro-organisms. In recent decades, the characteristics of this relationship have changed, which has given rise to the concepts of bio-object and biofactory. Based on these concepts, the present work aims to present the manufacturing process of a bioobject in Rio de Janeiro, Brazil: the Aedes aegypti mosquitoes with the bacteria Wolbachia. The analysis was made from bibliographic data and a field visit to the facilities of the biofactory under study.
\end{abstract}

Keywords. Bio-objects. Biofactories. Aedes aegypti. Wolbachia.

Resumo. Seres humanos se utilizam dos demais seres vivos como objetos, sejam estes animais, plantas ou micro-organismos. Nas últimas décadas, as características desta relação têm se alterado, o que fez surgir os conceitos de bio-objeto e de biofábrica. Amparado nestes conceitos, o presente trabalho tem como objetivo apresentar o processo produtivo de um bio-objeto no Rio de Janeiro, Brasil: os mosquitos Aedes aegypti com a bactéria Wolbachia. A análise foi feita a partir de dados bibliográficos e de uma visita de campo às instalações da biofábrica em estudo.

Palavras-chave. Bio-objetos. Biofábricas. Aedes aegypt. Wolbachia. 


\section{Introdução}

Os humanos sempre se utilizaram dos demais seres vivos e, de certa forma, os objetificaram. No entanto, nas últimas décadas, a relação dos humanos com os demais seres vivos tem apresentado novas características, incluindo a criação de novos seres vivos. Conceitos como o de bio-objeto e de biofábrica passam a ser utilizados para definir essas novas relações que se estabelecem.

O presente trabalho tem como objetivo apresentar o processo produtivo de um bio-objeto utilizado na área da saúde: os mosquitos com a bactéria Wolbachia. A parte conceitual e parte da descrição da produção de mosquitos foi baseada em levantamentos bibliográficos. A descrição da biofábrica se baseou ainda em uma visita técnica realizada a suas instalações. A visita, realizada em agosto de 2020, ocorreu em plena pandemia de Covid-19. O momento da visita, mesmo com todo empenho dos profissionais que me acompanharam, pode ter afetado a observação de atividades.

\section{Bio-objetos e biofábricas}

As recentes mudanças nas relações estabelecidas entre humanos e os demais seres vivos demandam uma reflexão inclusive do que se define como vida ou ser vivo. Esta definição tem tido uma mudança de escala, passando a ser consideradas vivas de estruturas intracelulares até macro-organismos. Ainda, como seres vivos devem ser considerados tanto organismos já existentes, independentes e capazes de se reproduzir, quanto novas entidades biológicas criadas e que estabelecem com os humanos novas funções e relações sociais. Estas novas entidades assumem, por vezes, um papel de destaque na agricultura, na área alimentar e na saúde (TAMMINE e VERMEULEN, 2019).

Surge, assim, o conceito de bio-objeto. Objeto, segundo o dicionário Caldas Aulete (LEXIKON, 2020), significa qualquer coisa material, mas também mercadoria e bem de consumo. O prefixo adicionado ao substantivo - bio - significa vida. O conceito de bioobjeto abrange produtos de manufatura biológica possibilitados pelas novas tecnologias da vida, que redirecionam, diversificam, colecionam ou mercantilizam os processos vitais (TAMMINE e VERMEULEN, 2019). São "hibridizações que não podem ser consideradas de natureza humana, animal, vegetal ou sintética" e que "desafiam os sistemas éticos, políticos e culturais tradicionalmente assentados" (COUTINHO, MATOS e SILVA, 2014, p.1948). A bio-objetificação ocorre quando organismos são transformados de forma que possam ser utilizados como objetos, como ferramentas pelos humanos.

Já o conceito de biofábrica é bastante amplo e podem ser encontradas diversas definições para o mesmo. Uma primeira definição é a do dicionário Caldas Aulete (LEXIKON, 2020): "unidade industrial e comercial de produtos geneticamente aperfeiçoados", como mudas de plantas, defensivos contra pragas, microrganismos, entre outros. Neste sentido, uma biofábrica é uma unidade industrial que produz seres vivos e seu conceito se vincula muito a melhoramento genético. Um segundo conceito de biofábrica refere-se à produção não de, mas por seres vivos, ou seja, os seres vivos não seriam produtos, mas meios de produção, como vemos citado pela Empresa Brasileira de Pesquisa Agropecuária Embrapa: "plantas, animais e microrganismos podem ser utilizados como biofábricas ou fábricas biológicas para produção de moléculas de alto valor agregado em larga escala e com baixo custo" (EMPRESA BRASILEIRA DE PESQUISA AGROPECUÁRIA, 2015).

Sejam os seres vivos produtos ou meios de produção, o que chama atenção no conceito de biofábrica é a possibilidade de objetificação de seres vivos diversos, plantas, animais 
e micro-organismos. Neste trabalho, utilizaremos o conceito de biofábrica como local de produção de seres vivos, não necessariamente de seres vivos geneticamente modificados ou clonados, mas de seres vivos de alguma forma modificados e utilizados em escala industrial.

\section{Aedes aegypti com Wolbachia}

A biofábrica que será descrita produz mosquitos Aedes aegypti com a bactéria Wolbachia. Esses mosquitos são fruto de um projeto desenvolvido pela Universidade de Monash, uma universidade australiana, cujo primeiro financiamento ocorreu por meio da Iniciativa para a Saúde Global, um edital coordenado pela Fundação Bill e Melinda Gates e pelo NationalInstitute for Health (NIH). O projeto teve início em 2005, na Austrália, com o objetivo de contribuir para o controle da população de Aedes aegypti com a utilização da bactéria Wolbachia (VARMUS, KLAUSNER, et al., 2003). Inicialmente, foi denominado "Eliminar a Dengue: nosso desafio", porém posteriormente foi renomeado para World Mosquito Program (WMP).

A bactéria Wolbachia infecta vários insetos na natureza desenvolvendo-se no interior de suas células e estabelecendo relações de simbiose com efeitos diversos. No entanto, até o desenvolvimento do projeto do WMP, a Wolbachia não infectava mosquitos Aedes aegypti. Para a produção desses mosquitos, a bactéria, após anos de adaptação em culturas de células, foi transferida da mosca-da-fruta para ovos de Aedes aegypti por meio de microinjeções (ITURBE-ORMAETXE, WALKER e O'NEIL, 2011 ). As pesquisas sobre a simbiose Aedes aegypti-Wolbachia demonstraram que os mosquitos resultantes apresentavam características diversas de acordo com a cepa da bactéria utilizada. A simbiose selecionada para produção e liberação no ambiente apresenta duas características centrais: forte incompatibilidade citoplasmática; e ação antiviral com relação aos vírus da dengue, da Zika, da Chikungunya e da febre amarela (MOREIRA, ITURBE-ORMAETXE, et al., 2009).

A incompatibilidade citoplasmática implica na interrupção do desenvolvimento de embriões que resultam quando as fêmeas são acasaladas com machos que têm um status de infecção diferente. Assim, as fêmeas com a bactéria quando acasaladas com machos, com Wolbachia ou não, transmitem a bactéria para a sua prole. Já os machos com a bactéria, ao acasalar com fêmeas sem Wolbachia, produzem ovos inviáveis (COOK, MCMENIMAN, SCOTT L O'NEILL e O'NEILL, 2008). O WMP propõe liberações em ambiente de mosquitos produzidos até que toda (ou quase toda) a população local de mosquitos Aedes aegypti esteja infectada com a bactéria Wolbachia. A proposta, portanto, do WMP não implica na supressão ou no controle populacional, mas na substituição das populações de mosquitos locais por mosquitos com capacidade reduzida de transmitir doenças.

\section{Uma biofábrica na Maré}

O projeto do WMP chegou ao Brasil em 2011, trazido pela Fundação Oswaldo Cruz Fiocruz. Atualmente, tem instalações no Rio de Janeiro, em Belo Horizonte e em outras cidades brasileiras. Aqui serão descritas as instalações localizadas no Campus Expansão da Fiocruz, na Avenida Brasil, na altura da favela da Maré. A figura a seguir busca esquematizar as atividades da biofábrica de mosquitos com Wolbachia no Rio de Janeiro. 


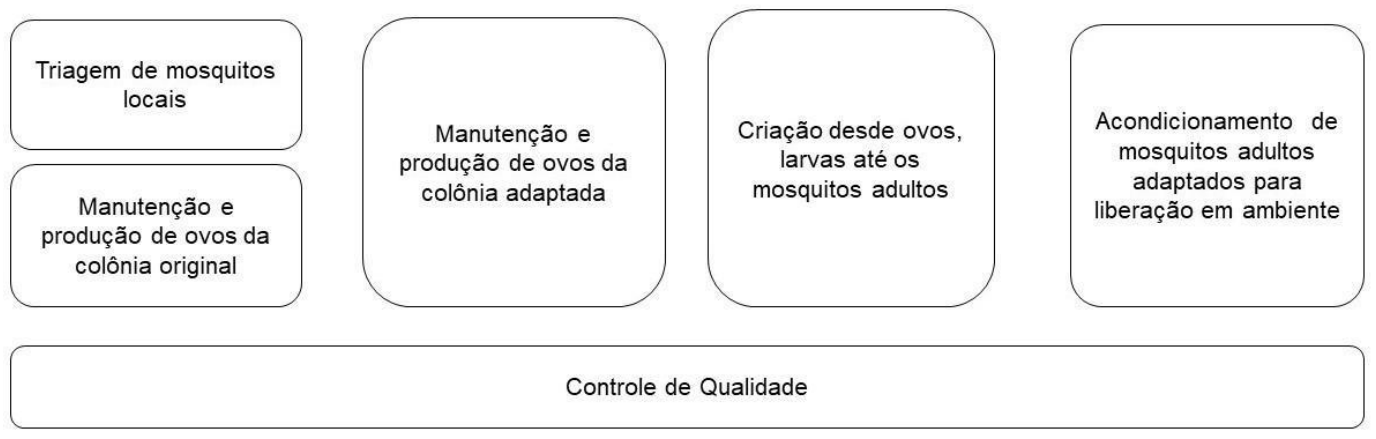

Figura 1. Biofábrica de Aedes aegypti com Wolbachia, instalada no Rio de Janeiro, segundo visita em 2020.

Fonte: Elaborada pelos autores.

Estas instalações se localizam em salas em três diferentes andares do prédio principal do Campus e em dois prédios próprios, construídos com recursos do projeto. No prédio principal do campus, além da equipe de gestão e da equipe de entomologia de campo, está instalado o Laboratório de Diagnóstico do WMP. Já nos dois prédios independentes, estão instaladas as demais estruturas da biofábrica.

O início do processo de produção da biofábrica tem dupla entrada de mosquitos. Uma primeira entrada é a chegada e a triagem de mosquitos locais, coletados pela equipe de entomologia de campo por meio de armadilhas instaladas em locais selecionados. A sala de recepção dos mosquitos locais está instalada logo na entrada do segundo andar do primeiro prédio. Nela trabalha, com a ajuda de microscópios, parte da equipe do Laboratório de Diagnóstico, que realiza o controle de qualidade da produção. A atividade desempenhada por esta parte da equipe é separar os Aedes aegypti dos mosquitos das demais espécies, também capturados nas armadilhas. Os mosquitos triados são enviados à estrutura do Laboratório de Diagnóstico localizado no prédio principal do campus.

A segunda entrada de mosquitos é a proveniente da colônia de mosquitos denominada de primeira amplificação. Estes mosquitos são a linhagem do início; uma amplificação proveniente da colônia matriz. Segundo pesquisadores da área de entomologia de laboratório, estes mosquitos são tratados "a pão de ló". O local é constituído por uma sala com cerca de 70 (setenta) gaiolas e cada gaiola abriga cerca de 2.000 (dois mil) a 2.500 (dois mil e quinhentos) mosquitos.

Os mosquitos desta colônia, além de serem alimentados com uma solução açucarada, são também alimentados com sangue proveniente de banco de sangue duas vezes por semana, necessário para que consigam se reproduzir. Em cada gaiola são colocadas canecas com fita no interior para captura de ovos. As canecas são retiradas a cada quatro dias. São coletados ovos dos mosquitos por quatro ciclos gonotróficos (períodos entre o repasto sanguíneo e a oviposição).

Ainda no primeiro prédio próprio do WMP, está instalada o que a equipe do projeto denomina de segunda amplificação de mosquitos. Nesta sala, encontram-se cerca de 240 (duzentos e quarenta) gaiolas, com 2.000 (dois mil) a 2.500 (dois mil e quinhentos) mosquitos cada. É uma sala similar à sala de primeira amplificação, apenas maior. Nesta sala, são produzidos mosquitos já adaptados ao ambiente do Rio de Janeiro. Esta adaptação foi realizada por meio do cruzamento de mosquitos "originais" com mosquitos locais; atividade que foi realizada em outra biofábrica do WMP, localizada em Belo Horizonte. O objetivo deste cruzamento foi o de liberar mosquitos com um perfil genético similar ao encontrado no ambiente local. No Rio de Janeiro, a característica buscada 
nestes cruzamentos foram os genes relacionados à resistência a inseticidas, muito presentes em mosquitos locais, mas não nos mosquitos trazidos da Austrália.

Como esta sala de segunda amplificação conta com um número muito superior de mosquitos se comparada à sala de primeira amplificação e como este é o local de preparo de canecas para coleta de ovos de ambas as salas, o que demanda a permanência de uma profissional no local por muitas horas, uma armadilha para mosquitos é deixada na sala para capturar os mosquitos que fogem. O objetivo desta estratégia é evitar incômodos para a profissional que trabalha no local. No momento da visita, verificamos a armadilha e havia dezenas de mosquitos capturados.

Os ovos coletados nesta sala são levados para o segundo prédio independente do projeto, denominado de Simulado de Campo, cuja construção foi anunciada, em 2017, pela Fiocruz (FUNDAÇÃO OSWALDO CRUZ, 2017). Segundo a notícia veiculada, o objetivo da estrutura é a produção em larga escala de mosquitos Aedes aegypti com Wolbachia, aumentando a capacidade de produção potencial de 600 mil para 1,6 milhão de ovos por semana, em um primeiro momento, podendo chegar a 10 milhões de ovos por semana (FUNDAÇÃO OSWALDO CRUZ, 2017).

O Simulado de Campo conta com um espaço para manutenção e estoque, uma sala para o desenvolvimento de ovos até a fase de pupa e uma sala para o desenvolvimento da pupa até a fase adulta (mosquito), que posteriormente são usados nas atividades de liberação no ambiente. Na visita realizada às instalações, as áreas de estoque e manutenção não foram incluídas.

A sala na qual os ovos eclodem e permanecem até a fase de pupa é um local com ambiente controlado, úmido e escuro. Sua estrutura é composta por um conjunto de estantes metálicas com bandejas, cerca de 90 em média. Cada bandeja abriga cerca de 22 mil larvas cada. As larvas são alimentadas com ração diariamente por sete dias; tempo em que chegam à fase de pupa.

As bandejas com as pupas são, então, transferidas para a segunda sala visitada no Simulado de Campo: a sala de acondicionamento em tubos para liberação de mosquitos no ambiente. Para esta sala, são levadas as bandejas contendo pupas. Ao chegar, profissionais mergulham manualmente tubos com uma peneira em uma das extremidades nas bandejas. Desta forma, as pupas são "coadas" e permanecem nos tubos. A extremidade sem peneira do tubo é, então, coberta com uma forma de tela a qual é presa com elástico. Esses tubos são parcialmente mergulhados em água por um período de quatro ou cinco dias até que as pupas se transformem em mosquitos. Como os tubos estão mergulhados apenas parcialmente na água, os mosquitos têm espaço para voar e são mantidos nos tubos pela cobertura de tela. Segundo informações coletadas no momento da visita, por semana, estavam sendo produzidos cerca de 6.000/6.500 tubos, cada um com cerca de 150 mosquitos.

Quando as pupas se transformam em mosquitos nos tubos, estes são levados pela equipe de entomologia de campo para liberações. No momento da visita de campo, as liberações dos mosquitos produzidos naquela biofábrica estavam sendo realizadas apenas na cidade do Rio de Janeiro.

Quanto às atividades de controle de qualidade, estas estão sob responsabilidade da equipe do Laboratório de Diagnóstico do WMP. Esta estrutura é utilizada com três objetivos, que acompanham todo o ciclo produtivo e seus resultados mais imediatos.

Um primeiro objetivo desta estrutura relaciona-se com o controle de qualidade do sangue que é utilizado para a alimentação dos mosquitos em laboratório. Esse sangue é obtido de 
bancos de sangue quando já impróprios para uso em humanos. Para a verificação da qualidade do sangue, ou seja, se este contém algum vírus, mosquitos Aedes aegypti sem Wolbachia (a presença da Wolbachia inibiria o desenvolvimento dos vírus pesquisados) são alimentados com o sangue e, após determinado período, são analisados e é avaliada a presença dos vírus da dengue, febre amarela, Zika, Chikungunya e Mayaro. Até o momento, não foi identificada nenhuma contaminação no sangue utilizado e, segundo pesquisadores, esta contaminação é improvável, uma vez que esses vírus são do tipo RNA e se degradam facilmente. A hipótese levantada é que, como o sangue utilizado para a alimentação dos mosquitos fica um longo período nos bancos de sangue, até passar seu prazo de validade para uso em humanos, caso houvesse alguma contaminação, com o tempo, esses vírus já teriam se degradado.

O segundo objetivo do Laboratório de Diagnóstico é comparar a genética dos mosquitos capturados nos futuros locais de liberação com a dos mosquitos que serão liberados. Como dito anteriormente, o WMP busca liberar mosquitos com perfil genético similar aos mosquitos locais, em especial, no Rio de Janeiro, no que se refere à resistência a inseticidas. Segundo pesquisadores entrevistados, há duas mutações genéticas ligadas à resistência a inseticidas. Para a produção de mosquitos com perfil semelhante aos mosquitos em termos de resistência a inseticidas, o WMP coleta mosquitos locais e cruza com mosquitos com Wolbachia. Geralmente com quatro ou cinco ciclos de cruzamento, chega-se a uma linhagem próxima à linhagem local de mosquitos. O Laboratório de Diagnóstico analisa o perfil genético destes mosquitos. Segundo pesquisadores entrevistados, no Rio de Janeiro, cerca de $100 \%$ dos mosquitos locais são resistentes a inseticidas. No caso de Campo Grande, por exemplo, apenas $20 \%$ apresentam os genes relacionados à resistência a inseticidas. Esse perfil genético está relacionado a uma pressão imposta pelas escolhas nas tecnologias de controle de arboviroses, ou seja, pela forte utilização de inseticidas (larvicidas ou adulticidas).

É ainda esta estrutura que verifica a presença da bactéria Wolbachia no organismo dos mosquitos Aedes aegypti coletados em campo. Esta verificação serve como indicador do estabelecimento da bactéria em uma determinada população local de mosquitos após as liberações: é uma parte do monitoramento por meio da qual se verifica o percentual de presença da Wolbachia na população de mosquitos de uma determinada área. O esquema a seguir busca demonstrar de forma simplificada as entradas, atividades e entregas da Biofábrica em estudo. 


\section{Biofábrica de Aedes aegypti com Wolbachia, Rio de Janeiro}
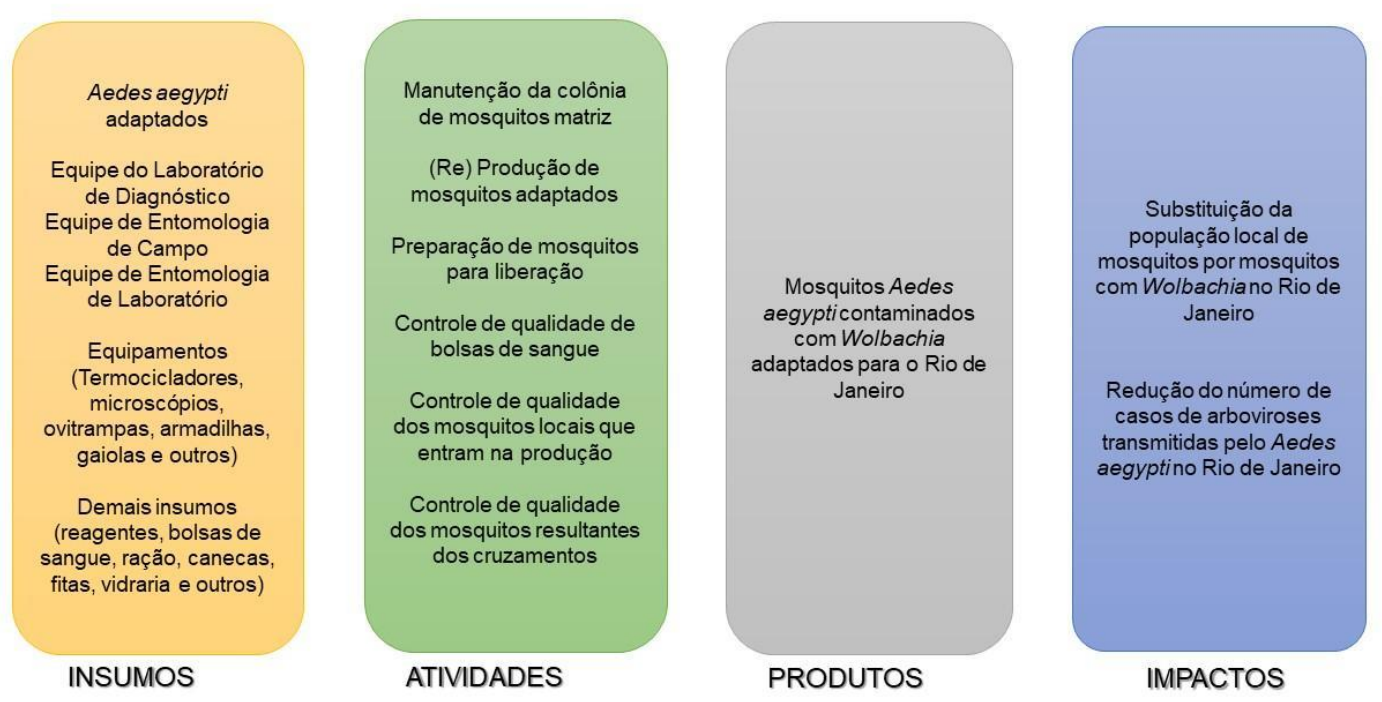

Figura 2. Biofábrica de Aedes aegypti com Wolbachia, Rio de Janeiro (parte em Belo Horizonte), visita de 2020.

Fonte: Elaborada pelos autores.

Como vimos, os principais insumos para a produção dos mosquitos liberados em cidades do Rio de Janeiro são os Aedes aegypti com Wolbachia adaptados por meio de cruzamentos de mosquitos com Aedes aegypti coletados localmente. A prole dos é (re)produzida e acondicionada em tubos para posterior liberação. Para tanto, é necessário o trabalho direto de três equipes de profissionais com perfis diversos: a entomologia de campo, a entomologia de laboratório e o laboratório de qualidade. O impacto mais imediato esperado, pós-liberações, é a substituição da população local de mosquitos por uma população de mosquitos com a bactéria Wolbachia, com capacidade vetorial reduzida. O impacto potencial esperado para o futuro é a redução do número de casos de arboviroses nas áreas tratadas com a tecnologia.

\section{Considerações finais}

A biofábrica descrita transforma organismos - os mosquitos Aedes aegypti locais - em ferramentas para serem utilizados em políticas de saúde pública. Este processo pode ser definido como bio-objetificação, um processo no qual, por meio de trabalho científico, seres vivos são transformados, produzidos em massa, regulados e empregados como ferramentas pelos humanos. Os bio-objetos devem ser pensados não apenas como resultados, mas também como geradores de e constituídos por um conjunto de relações e práticas coletivas ((TAMMINE e VERMEULEN, 2019), que constituem uma rede sociotécnica.

Especificamente, os mosquitos com a bactéria Wolbachia podem ser compreendidos em diferentes dimensões. Esses mosquitos são novos produtos vivos, resultantes da aplicação de novas técnicas das biotecnociências. Os mosquitos originários da Austrália já eram uma nova entidade criada em laboratório, fruto da simbiose Aedes aegypti-Wolbachia. No Rio de Janeiro, são ainda adaptados, por meio de cruzamentos, com Aedes aegypti 
locais. A biofábrica cria, então, uma nova entidade, transformando a identidade do Aedes aegypti, que deixa de ser visto como "inimigo" e passa a ser uma ferramenta para o controle de doenças. Estas novas entidades, cujo comportamento no ambiente ainda não é totalmente conhecido, são autônomas e sujeitas a pressões evolutivas.

Esses novos mosquitos podem ser ainda abordados como modificações funcionais em corpos, neste caso de animais, gerando corpos reconfigurados. Em geral, este tipo de abordagem é pensada para corpos humanos, mas esta tecnologia reconfigura corpos de animais, com o objetivo de substituir toda uma população local e, pode-se dizer, selvagem, por uma população mais domesticada, inofensiva aos humanos. Suas características físicas são modificadas, assim como sua reprodução e sua capacidade vetorial. O conjunto de modificações que estão sendo provocadas nos corpos dos mosquitos não é totalmente compreendido.

Finalmente, esses bio-objetos podem ser percebidos como mercadorias, como bens negociáveis em nível global e que geram, ao mesmo tempo, temores e expectativas. No Brasil, e nos demais países onde é implementado, o WMP se configura como uma iniciativa sem fins lucrativos. No entanto, o volume de recursos movimentado é significativo e as áreas onde sua negociação é viável compreendem boa parte das regiões tropicais e subtropicais do mundo. Os desafios para sua regulação e controle nos países onde estão sendo e serão adotados serão imensos.

\section{Agradecimentos}

O apoio da equipe do World Mosquito Program do Rio de Janeiro que acompanhou a visita às instalações do projeto no Rio de Janeiro e revisou o presente texto foi imprescindível para a realização deste trabalho.

\section{Financiamento}

O presente trabalho foi realizado com apoio da Coordenação de Aperfeiçoamento de Pessoal de Nível Superior - Brasil (CAPES) - Código de Financiamento 001.

\section{Referências bibliográficas}

COOK, P. E. et al. Modifying insect population age structure to control vector-borne disease. AdvExp Med Biol, 627, 2008. 126-140. Disponivel em: $<$ https://pubmed.ncbi.nlm.nih.gov/18510020/>. Acesso em: 17 março 2020.

COUTINHO, F. Â.; MATOS, Á. D.; SILVA, A. R. E. Mapeando as relações entre ciência, tecnologia, sociedade e ambiente (CTSA) por meio dos bio-objetos. Revista de Ensino de Biologia da Associação Brasileira de Ensino de Biologia, SBEnBio, 7, $2014 . \quad$ 1943-1952. Disponivel em: $<$ https://www.repositorio.ufop.br/handle/123456789/8450>. Acesso em: 09 novembro 2020 . 
EMPRESA BRASILEIRA DE PESQUISA AGROPECUÁRIA. Fábricas biológicas. EMBRAPA, 15 julho 2015. Disponivel em: <https://www.embrapa.br/busca-denoticias/-/noticia/3624041/fabricas-biologicas>. Acesso em: 23 setembro 2020.

FUNDAÇÃO OSWALDO CRUZ. Fiocruz libera Aedes com Wolbachia no Rio de Janeiro. Portal Fiocruz, 29 agosto 2017. Disponivel em: $<$ https://portal.fiocruz.br/noticia/fiocruz-libera-aedes-com-wolbachia-no-rio-dejaneiro $>$. Acesso em: 12 junho 2020.

ITURBE-ORMAETXE, I., WALKER, T., O' NEILL, S.L. Wolbachia and the biological control of mosquito-borne disease. EMBO Rep, 12, n. 6, 6 maio 2011. 508-518. Disponivel em: <https://pubmed.ncbi.nlm.nih.gov/21546911/>. Acesso em: 15 julho 2017.

LEXIKON. Dicionário Aulete Digital. Aulete, 2020. Disponivel em: $<$ http://www.aulete.com.br>. Acesso em: 09 novembro 2020.

MOREIRA, L. A. et al. A Wolbachia Symbiont in Aedes aegypti. Cell, 7, n. 24, 24 dezembro 2009. 1268-1278. Disponivel em: $<$ http://www.eliminatedengue.com/library/publication/document//moreira_et_al_2009.p df>. Acesso em: 09 agosto 2019.

TAMMINE, S.; VERMEULEN, N. Bio-objetos: novas conjugações do viver. Sociologias, Porto Alegre, 21, n. 50, jan-abr 2019. 156-179. Disponivel em: $<$ https://www.scielo.br/scielo.php?script=sci_arttext\&pid=S1517-

45222019000100156\&lng=pt\&nrm=iso\&tlng=pt>. Acessoem: 09 novembro 2020.

VARMUS, H. et al. PUBLIC HEALTH: Grand Challenges in Global Health. Science, 302, n. 5644, 17 outubro 2003. 398-399. Disponivel em: $<$ https://www.ncbi.nlm.nih.gov/pmc/articles/PMC243493/>. Acesso em: 21 julho 2018. 